\title{
Relationship between Stereological Analysis and Toughness of Microalloyed Steels of Equivalent Strength
}

\author{
R. D. K Misra, ${ }^{* 1,2}$ and S. Shanmugam, ${ }^{1,2}$ \\ ${ }^{*}$ Center for Structural and Functional Materials \\ ${ }^{* 2}$ Department of Chemical Engineering \\ University of Louisiana at Lafayette, Lafayette, LA 70504-4130, USA
}

Stereological analysis involves relating three-dimensional microstructural parameters namely volume fraction, surface area per unit volume, length per unit volume, and number per unit volume to the observations made on two-dimensional images of microstructures. Classical stereology concerns relationship between measurements on two-dimensional plane-section images and the stereological parameters. From the measurements, mean and standard deviations are obtained and related to three-dimensional parameters of the microstructure using fundamental relationships.

Microalloyed steels are becoming increasingly attractive for structural applications because thermomechanical processing and alloy design can be controlled to obtain different microstructures with varying strength-toughness combination [1]. Our recent work on hot rolled microalloyed steels indicated that the application of $\mathrm{Nb}$-Ti microalloying approach improves formability and toughness [2], a behavior attributed to fine grain size, narrow grain size distribution, inherently ductile behavior and microplasticity, reduced intensity of undesirable $\{100\}<011>$ texture and higher intensity of desired $\{332\}<113>$ texture. This improved behavior was in contrast to equivalent strength V-steels. The present paper underscores the effective application of stereological analysis in understanding the underlying factors responsible for superior toughness of microalloyed steels that are characterized by almost similar strength and microstuctural constituents. An analysis of $\mathrm{V}$-, $\mathrm{Nb}$-, and V-Nb-Ti microalloyed steels with yield strength of $400 \mathrm{MPa}$ is described here. The microstructures of different steels were quantified in terms of stereological parameters, notably mean intercept length $\left(\overline{\mathrm{L}}_{\alpha}\right)$ of polygonal ferrite, pearlite colony and their size distribution, ferrite grain boundary surface area per unit volume $\left[\mathrm{S}_{\mathrm{V}}\right]_{\alpha}$, total grain boundary surface area per unit volume $\left[\mathrm{S}_{\mathrm{V}}\right]_{\mathrm{T}}$, contiguity ratio $\left(\mathrm{C}_{\alpha}\right)$ of ferrite grains and pearlite colonies, pearlite interlamellar spacing and its distribution.

In $\mathrm{V}$ - and $\mathrm{V}-\mathrm{Nb}$-Ti steels, stereological analysis of core and flange sections of load-bearing structural components indicated that the core and flange section of $\mathrm{V}$-steel are characterized by a relatively finer ferrite grain size and narrow grain size distribution, higher contiguity ratio of ferrite grains, fine pearlite interlamellar spacing and its distribution, and uniform distribution of pearlite colony size in comparison to respective core and flange sections of the V-Nb-Ti steel. These characteristics have a profound influence on toughness. In Figure 2, the variation of impact energy as a function of ferrite grain size and ferrite contiguity ratio is presented. Figure 2 demonstrates that the impact energy is linearly related to contiguity ratio and mean intercept length. 


\section{References:}

[1] R. D. K. Misra, G. C. Weatherly, J. E. Hartmann, and A. J. Boucek: Mater. Sci. Tech., 17, (2001) 1119.

[2] R. D. K. Misra, K. K Tenneti, G. C. Weatherly and G. Tither: Metall Trans., 34A, (2003) 2341.
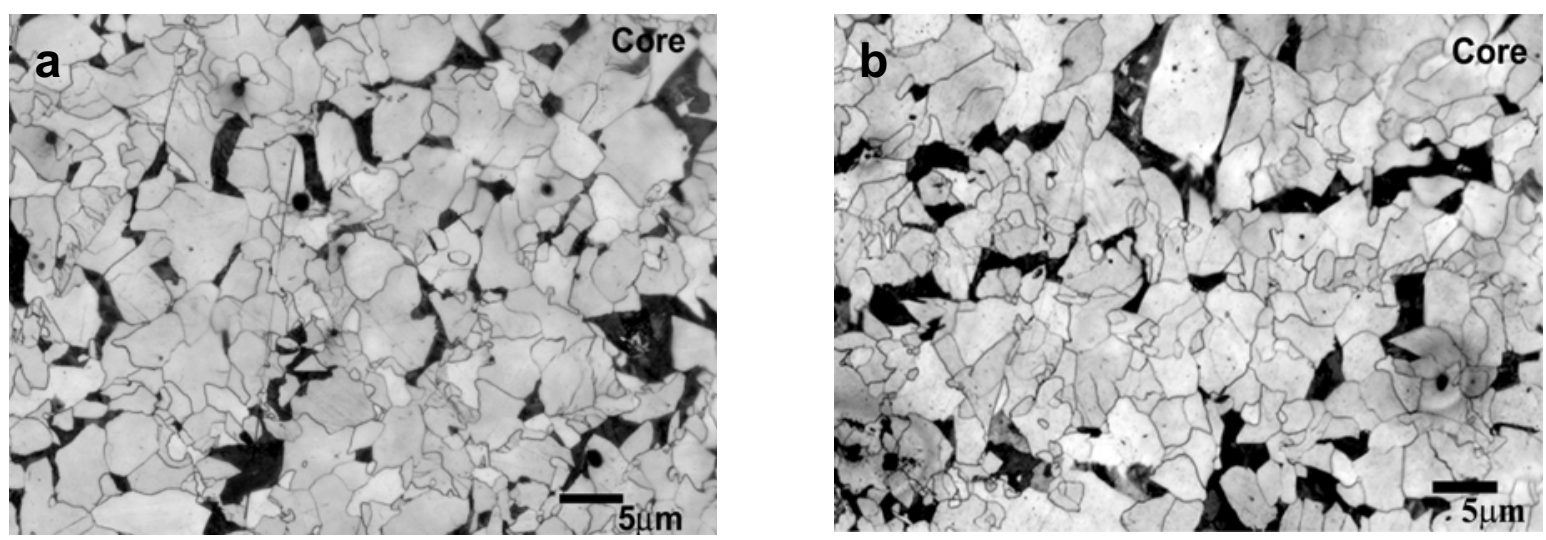

Figure 1: Ferrite-pearlite microstructure of (a) V-Nb-Ti and (b) V-steel of similar strength (400 $\mathrm{MPa}$ ) but exhibiting significant differences in toughness.

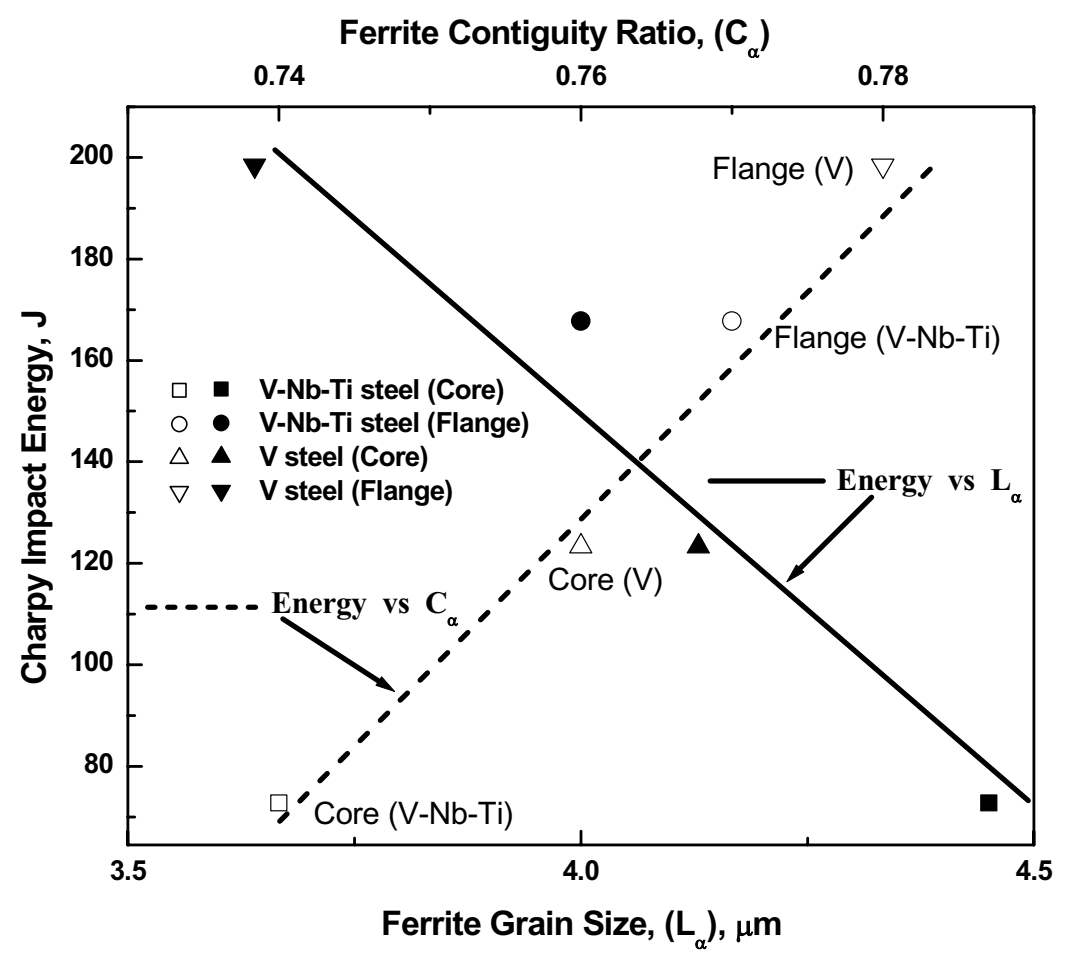

Figure 2: Charpy impact energy as a function of ferrite grain size and contiguity ratio for core and flange sections of similar strength $\mathrm{V}-\mathrm{Nb}-\mathrm{Ti}$ and $\mathrm{V}$-steels. Note the linear relationship. 